\title{
REVIEW
}

\section{Beta-blocker therapy of cardiovascular diseases in patients with bronchial asthma or COPD: The pro viewpoint}

\author{
Houman Ashrafian*, Andonis G. Violaris
}

Department of Cardiology, Northwick Park Hospital, Watford Road, Harrow, Middlesex HA1 3UJ, UK

Received 17 April 2005; accepted 30 June 2005

\section{KEYWORDS}

Beta blockers;

Asthma;

Chronic obstructive

pulmonary disease

(COPD);

Cardiovascila:

Myocardial infarction;

Heart failure (CHF)

\begin{abstract}
Summary Extensive randomised clinical trial date cipport tire view that $\beta$ blockers have a significant impact on the p $d$ gin s of patients with cardiovascular disease, especiallv those witr Cofonary artery disease and chronic heart failure. Unfortunately thi: essential creatment is " $\mathrm{ften}$ withheld from patients with asthma anderipesense patients with Chor ic (ob stiuctive Pulmonary Disease (COPD). The principal concern a conde $n$. pported by a number of guidelines, is that $\beta$-blockers may pre(if) tatel severe and potentially fatal bronchospasm. However, a number of sticies, culminating in a recent meta-analysis, show that cardioselective $\beta$ blockers are not only safe but are beneficial in patients with co-existing airways and coronary disease. In this article we review the evidence supporting the position that cardioselective $\beta$-blockers, when introduced with care in both community and hospital settings, are safe in patients with mild airways disease and can significantly improve prognosis.

( $) 2005$ General Practice Airways Group. Published by Elsevier Ltd. All rights reserved.
\end{abstract}

\section{Contents}

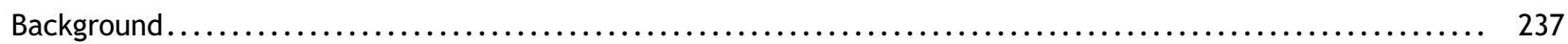

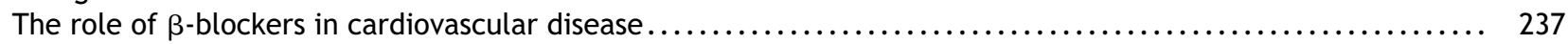

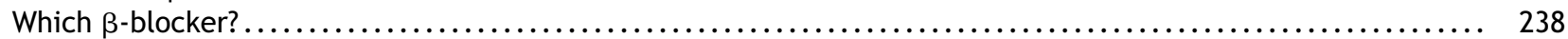

Evidence for the safety of $\beta$-blockers in airways disease......................................... 238

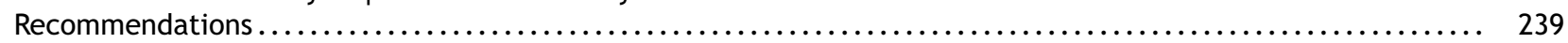

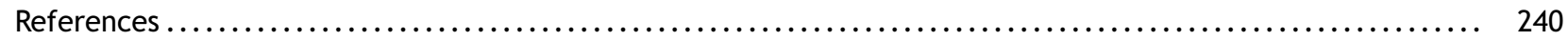

* Corresponding author.

E-mail address: ashrafian@hotmail.com (H. Ashrafian). 


\section{Background}

$\beta$-blockers have transformed the practice of medicine. Commenting on Sir James Black's Nobel-winning work to discover propranolol, the first $\beta$-blocker, the Nobel Committee in 1988 commended us to remember that these agents were "the greatest breakthrough when it comes to pharmaceuticals against heart illness since the discovery of digitalis 200 years ago."'[1] Despite pharmaceutical advances in all of medicine, informed by a rapidly evolving research base, $\beta$ blockers remain one of the fundamental mainstays of treatment in patients with cardiovascular disease. In the face of such compelling data, it is therefore surprising that $\beta$-blockers are still underused, particularly in those with airways disease [2-4]. This statistic is less surprising when it is noted that even the European Society of Cardiology (ESC) guidelines [5] suggest that in general, $\beta$-blockers should be used with care in obstructive airways disease.

The principal concern derives from the wellrecognised capacity of $\beta$-adrenoreceptor blockade to cause bronchoconstriction. It has generally been assumed that the detrimental effect of $\beta$ blockers on the airways results directly from simp'e post-synaptic $\beta$-2-adrenoreceptor antagcnirg th $s$ assumption is partially suppor ed to the view that bronchccoristriction Cccurs more frequen \&y with non-selective $\beta$-blocking Eofs than with selective $\beta-1$ antagonists. It is worth noting in passing that the detrimental effects of $\beta$ blockers are complex and may be related to presynaptic $\beta$-adrenoreceptor blockade, effects on the cholinergic $M 2$ receptors, and effects on $\alpha-1$ adrenoreceptors. The respiratory consequences of $\beta$-blockers may therefore transcend their simple $\beta 1 / \beta 2$ selectivity. Moreover, traditional published data on receptor selectivity has been recently challenged by work on receptor properties studied in the context of whole cells; these studies suggest that most existing $\beta$-blockers appear to be less $\beta-1$ selective than thought [6].

Clinically, the corresponding respiratory consequences of $\beta$-adrenoreceptor blockade have been principally derived from small studies, case-reports and editorials [7-10]. One example of the small size of these limited studies is a study assessing the detrimental effects of $\beta$-blockers in COPD; while published in a leading respiratory journal as being essentially a physiological study, it made clinical recommendations on the basis of 15 patients treated and studied after 4 days [11]. While these and other studies have underlined the capacity of non-cardioselective $\beta$-blockers to cause respiratory deterioration and occasionally fatal bronchospasm, a suspicion supported by anecdotal experience of patients who complain of wheeze or breathlessness associated with these agents, the question remains as to whether these agents are objectively detrimental.

In this viewpoint review, we intend briefly to review the evidence that $\beta$-blockers are indeed useful in cardiovascular disease, give an account of the pharmacology of $\beta$-blockers, provide a scientific and clinical rationale to justify the use of $\beta$-blockers in patients with obstructive airways diseases, and finally, review the evidence confirming the safety of these agents. Our viewpoint is that, if used carefully (as detailed below), $\beta$-blockers may represent efficacious therapy in patients with both cardiovascular and obstructive airways disease.

\section{The role of $\boldsymbol{\beta}$-blockers in cardiovascular disease}

Whilst the role of $\beta$-olo-kels a variety of cardiovasculail (dis:eases is well recognised, the nio t Gorivincing benefits have been documented tor patient huit Onyocardial infarction, both perio [12] arda post-infarction $[13,14]$. The acute $15 \%$ mortality benefit clearly extends into the post-infarct period [15]. This prompted the 2001 American Heart Association and American College of Cardiology guidelines to recommend initiating $\beta$-blockade in all post-Ml patients and for therapy to continue indefinitely [16]. There is also extensive evidence supporting the use of $\beta$-blockers in heart failure [17], unstable angina [18-21], hypertension, arrhythmias and thyrotoxic cardiac disease. While traditionally the indications for $\beta$-blocker treatment have been determined by underlying cardiovascular aetiology, it is also important to note that $\beta$-blockers may be especially valuable at times of systemic stress. One example of this temporal- as well as aetiologybased application for $\beta$-blockers is in the context of surgery; there is an overwhelming body of evidence suggesting that a reduction in cardiac endpoints can be achieved by perioperative $\beta$-blockade [22,23].

The prevalence of COPD in patients with chronic heart failure (CHF) is known to range from 23\% to $33 \%[24,25]$; this figure is set to increase with an increase in airways disease out of proportion to the demographic transition. Furthermore there is extensive evidence in a variety of settings, such as acute myocardial infarction, that patients 
with airways disease accrue significant benefit from $\beta$-blocker therapy [26]. Clearly, despite the inevitable complexity involved in treating patients with multiple co-morbidities, the failure to institute $\beta$-blockade in patients with airways disease represents a missed opportunity.

Despite this wealth of evidence, an observational study of approximately 200,000 patients found that only $34 \%$ of patients received $\beta$-blockers postinfarction [4]. A number of subgroups such as the elderly, diabetic patients, and patients with COPD, were especially under-treated with these agents. When treated, even these subgroups of patients accrued a mortality benefit. This confirms the assertion that patients in these subgroups probably represent patients with the highest absolute risks and hence may paradoxically benefit most from $\beta$ blockade.

This omission has led the American Medical Association to issue a Clinical Quality Improvement recommendation that supports the use of $\beta$ blockers in reducing mortality and specifically states that the absolute magnitude of benefit is sufficiently striking to outweigh their risks, even in patients with relative contraindications such as asthma, diabetes mellitus, COPD, severe peripheral vascular disease, or presence of $P R$ interval $>0.24$ seconds. Three question. Pemain. which $\beta$-blocker; what ic the specutic evidence for $\beta$-blocker use in patients with airway's dis=ase; and how practically shoulc tîp-biocker be introduced? In order to answer these questions, a basic review of the pharmacology of these agents is necessary.

\section{Which $\beta$-blocker?}

Clear differences exist between different $\beta$ blockers with respect to their pharmacokinetics, receptor selectivity, lipophilicity, and intrinsic sympathomimetic activity. These differences translate into clear prognostic distinctions; one controversial example relates to the comparison of $\beta$-blockers in heart failure. The COMET study compared the efficacy of carvedilol, a non-selective $\beta$-blocker with $\beta 1-, \quad \beta 2$ - and $\alpha$-adrenoceptor antagonist properties, with the $\beta 1$-selective agent metoprolol in chronic heart failure. While the differences in the effective pharmacological dose of these agents used in the study have been noted, the COMET investigators concluded that all-cause mortality was lower in the carvedilol than the metoprolol group [27].

With respect to airways disease, it has been argued that $\beta-2$ adrenoceptor antagonism is the most detrimental mediator of $\beta$-blocker therapy. Consequently, it has been recommended that for the sake of maximum safety 'cardioselective' or $\beta$-blockers with specifically $\beta 1$ adrenoceptor antagonism should be used [5]. It must be noted, however, that the myocardium does express $\beta-2$ adrenergic receptors and the potentially beneficial effect of $\beta 2$ adrenoceptor antagonism should not be completely discounted.

Following the success of chronic $\beta$-blocker therapy in heart failure, it became clear that part of the benefit derived from the reversal of adrenoceptor downregulation in chronically sympathetically-stimulated hearts. The same principle has been applied to asthma - whilst the subject of controversy, some investigators have tentatively hypothesised that chronic $\beta$-blockade may be similarly effective in asthma [28]. Indeed FDA approval for a clinical study using nadolol has been obtained [29].

\section{Evidence for the safety of $\beta$-blockers in airways disease}

irl the Gight of prognostic evidence supporting the use of $\beta-b l$ ro kes in cardiovascular disease, many pliysicians nave successfully used these agents in patients with airways disease, even though there was little evidence to support their position. Many used these agents inconsistently and with reluctance because of the potential respiratory sequelae, especially in primary care [30]. In truth, a number of studies, many of them randomised, blinded and placebo-controlled (RCTs) have been available.

Systematic Cochrane Database Reviews (2002) and further meta-analyses by Salpeter et al. at Stanford University of RCTs of patients with reversible airway disease and COPD exposed to single dose or continued treatment with cardioselective $\beta$-blockers have been published [31-34]. Although they found that acute (single dose) $\beta$-blockade resulted in a small mean $7.46 \%$ $(95 \% \mathrm{Cl} 5.59,9.32)$ reduction in $\mathrm{FEV} 1$, this was mitigated by a $4.63 \%(95 \% \mathrm{Cl} 2.47,6.78)$ increase in FEV1 with $\beta-2$ agonists. Moreover, chronic treatment ( $3-28$ days) produced no change in FEV1 $(-0.42 \% ; 95 \% \mathrm{Cl}-3.74,2.91)$, symptoms, or inhaler use, whilst inducing an $8.74 \%(95 \% \mathrm{Cl} 1.96,15.52)$ response to $\beta-2$ agonists. Indeed, of the 80 trials identified, no consistent exacerbation of airways disease was recorded.

Certain inevitable provisos exist when metaanalyses of this sort are considered. As well as 
having to accept a heterogeneous group of patients and/or studies with inevitable publication bias, most of the included studies are small. Whilst the use of meta-analyses may appear to overcome this deficiency, there is a significant risk of a type II statistical error in each of these studies. Notwithstanding publication bias, the latter error (a chance error resulting from the small size of a study) appears less likely in this field since the trend in most studies was towards efficacy and safety.

The most compelling concern is that, even if these studies are taken at face value and are correct, the long-term safety of $\beta$-blockers in airways disease has not been proven. The studies were limited to 28 days, excluded patients who had recent exacerbations and were deemed to be at higher-risk, generally included younger patients, and may have been subject to publication bias. Nevertheless, the authors concluded that cardioselective $\beta$-blockers given to patients with mild-moderate reversible airway disease or COPD produced no adverse respiratory effects in the short term. Given their demonstrated cardiovascular benefit the authors suggested that these agents should not be withheld; they did, however, cautiously call for longer-term studies. While indications such as acute myocardi it infarction are less controversial siven the vealth of prognostic evidence suppoting solocker use these recomriendiatidns have been recent's er:hoed in hypertension [35] and hear f fid. 110 [36] and represent a prevailing view in the literature.

\section{Recommendations}

Although the ESC guidelines recommend caution with the use of $\beta$-blockers in bronchial asthma or severe bronchial disease, little evidence is cited to support this position [5]. Moreover the 2002 consensus had been reached and published prior to the publication of the Salpeter meta-analysis. Given the evidence presented above, we agree that $\beta$-blockers should not be withheld in patients with mild-moderate well-controlled asthma [37]. This statement is made subject to a number of caveats:

(a) The asthma or COPD must be clinically mildmoderate and well-controlled as judged by the British Thoracic Society (BTS)-Scottish Intercollegiate Guidelines Network (SIGN) [38] and The Global Initiative for Asthma (GINA)/NHLBI/World Health Organization (WHO) guidelines [39]. As well as there being no features in the patient's history suggesting a predisposition to severe exacerbations, the
Table 1 Cardioselective vs Noncardioselective $\beta$ blockers.

\begin{tabular}{ll}
\hline $\begin{array}{l}\text { Cardioselective }(\beta 1 / \beta 2 \\
\text { selectivity) }\end{array}$ & $\begin{array}{l}\text { Noncardioselective } \\
(\beta 1 / \beta 2 \text { selectivity) }\end{array}$ \\
\hline Acebutolol & $\begin{array}{l}\text { Carvedilol }(7.3) \\
\text { Atenolol }(75)\end{array}$ \\
Bisoprolol $(119)$ & nadololol \\
Celiprolol $(\sim 300)$ & oxprenolol \\
Esmolol $(70)$ & pindolol \\
Nebivolol $(293)$ & Propranolol $(2.1)$ \\
Metoprolol $(74)$ & timolol \\
\hline
\end{tabular}

peak flow rate must be at least $70 \%$ of best or predicted (ideally $>80 \%$ ) and the variability $<30 \%$. The patient must be optimally medicated with inhaled corticosteroids, and long- and short-acting $\beta-2$ adrenoceptor agonists as appropriate. Should these agents be withheld from patients who have exacerbations of airways disease? In the absence of clear evidence no definitive position can be advocated, but pragmatically it would be sensible to persist with thesle asents during mild exacerbation; Sthat can be effectively contiolld dit the community with inhalers and oral steroids. It would equally seem prudeh to withinold these agents during major exacerbations requiring hospital admission. Moreover, in the latter patients and those with frequent exacerbations, $\beta$-blockers should be used with extreme caution if at all.

(b) Cardioselective $\beta$-blockers (see Table 1 ) should be used at the lowest dose and titrated slowly with attention to peak flow and symptoms. This is rather akin to the introduction of $\beta$ blockers in those patients with heart failure, a process previously restricted to specialists only, but now these agents can be introduced in any medical setting. Whether this is done in primary or in tertiary care, the key is adherence to simple and well-known principles of gradual titration with regular monitoring [5].

(c) Patient education and partnership should be garnered to ensure an appreciation of the potential benefits of these agents and early presentation with respiratory sequelae to facilitate $\beta$-blocker modification.

(d) Patients should be enrolled as part of a registry to assess the long-term benefits and sequelae of $\beta$-blockers in airways disease, be these positive [29] or negative.

Whilst the use of $\beta$-blockers in airways disease remains controversial, a considerable body of evidence suggests that, if used correctly, the 
prognostic benefits for patients are sizeable. In the absence of a desperately needed longterm randomised controlled trial, the Class I evidence from meta-analyses should be considered. Moreover, there is a need for physicians cognisant of the benefits and potential harm of these agents to apply them carefully to low-risk respiratory patients with high-risk cardiac conditions in order to reduce the patients' global risk. This represents a compelling challenge in our comorbid ageing population.

\section{References}

[1] Radford MJ, Krumholz HM. Beta-blockers after myocardial infarction-for few patients, or many? N Engl J Med 1998;339(8):551-3.

[2] Everly MJ, Heaton PC, Cluxton Jr RJ. Beta-blocker underuse in secondary prevention of myocardial infarction. Ann Pharmacother 2004;38(2):286-93.

[3] Dart RA, Gollub S, Lazar J, Nair C, Schroeder D, Woolf SH. Treatment of systemic hypertension in patients with pulmonary disease: COPD and asthma. Chest 2003;123(1):222-43.

[4] Gottlieb SS, McCarter RJ, Vogel RA. Effect of beta-blockade on mortality among high-risk and low-risk patients after myocardial infarction. N Engl J Med 1998;339(8):489-97.

[5] Task Force for the Diagnosis and Treatment of Chronic reart: Failure ESoC, Remme WJ, Swedbero O Guidelines for the diagnosis and treatment of thronic heart failure. Eur $\mathrm{Hed}_{\mathrm{e}} \mathrm{t}$ J 2001; 22(1): 15):-60.

[6] Baker JG. The selectivity of beta a denceptor antagonists at the human beta1, beta2 and beta3 adrenoceptors. Br J Pharmacol 2005;144(3):317-22.

[7] Craig T, Richerson HB, Moeckli J. Problem drugs for the patient with asthma. Compr Ther 1996;22(6):339-44.

[8] Tattersfield AE. Respiratory function in the elderly and the effects of beta blockade. Cardiovasc Drugs Ther 1991;4(Suppl 6):1229-32.

[9] Tattersfield AE. Beta adrenoceptor antagonists and respiratory disease. J Cardiovasc Pharmacol 1986;8(Suppl 4):35-9.

[10] Tattersfield AE, Holgate ST, Harvey JE, Gribbin HR. Is asthma due to partial beta-blockade of airways? Agents Actions Suppl 1983;13:265-71.

[11] van der Woude HJ, Zaagsma J, Postma DS, Winter TH, van Hulst M, Aalbers R. Detrimental effects of beta-blockers in COPD: a concern for nonselective beta-blockers. Chest 2005;127(3):818-24.

[12] Randomised trial of intravenous atenolol among 16027 cases of suspected acute myocardial infarction: ISIS-1. First International Study of Infarct Survival Collaborative Group. Lancet 1986;2(8498):57-66.

[13] Freemantle N, Cleland J, Young P, Mason J, Harrison J. beta Blockade after myocardial infarction: systematic review and meta regression analysis. BMJ 1999;318(7200):1730-7.

[14] Frishman WH, Furberg CD, Friedewald WT. Beta-adrenergic blockade for survivors of acute myocardial infarction. $\mathrm{N}$ Engl J Med 1984;310(13):830-7.

[15] Gheorghiade M, Goldstein S. Beta-blockers in the postmyocardial infarction patient. Circulation 2002;106(4): 394-8.
[16] Smith Jr SC, Blair SN, Bonow RO, et al. AHA/ACC Scientific Statement: AHA/ACC guidelines for preventing heart attack and death in patients with atherosclerotic cardiovascular disease: 2001 update: A statement for healthcare professionals from the American Heart Association and the American College of Cardiology. Circulation 2001;104(13):1577-9.

[17] Farrell MH, Foody JM, Krumholz HM. beta-Blockers in heart failure: clinical applications. JAMA 2002;287(7):890-7.

[18] Telford AM, Wilson C. Trial of heparin versus atenolol in prevention of myocardial infarction in intermediate coronary syndrome. Lancet 1981;1(8232):1225-8.

[19] Gottlieb SO, Weisfeldt ML, Ouyang P, et al. Effect of the addition of propranolol to therapy with nifedipine for unstable angina pectoris: a randomized, double-blind, placebo-controlled trial. Circulation 1986;73(2):331-7.

[20] Lubsen J, Tijssen JG. Efficacy of nifedipine and metoprolol in the early treatment of unstable angina in the coronary care unit: findings from the Holland Interuniversity Nifedipine/metoprolol Trial (HINT). Am J Cardiol 1987;60(2):18A-25A.

[21] Yusuf S, Wittes J, Friedman L. Overview of results of randomized clinical trials in heart disease. II. Unstable angina, heart failure, primary prevention with aspirin, and risk factor modification. JAMA 1988;260(15):225963.

[22] Mangano DT, Layug EL, Wallace A, Tateo I. Effect of atenolol on mortality and cardiovascular morbidity after noncardiac surgery. Multicente Stucy of Perioperative Ischemia "Research Ci Oup. N Enst J Med 1996;335(23): 1713-ic. IN J

[23] Podermans D, Boprsma E, Bax JJ, et al. The effect of bisopiold on $\lrcorner$ erioperative mortality and myocardial ivar ticn in higi-risk patients undergoing vascular surgery. Dutch Echocardiographic Cardiac Risk Evaluation Applying Stress Echocardiography Study Group. N Engl J Med 1999;341(24):1789-94.

[24] Havranek EP, Masoudi FA, Westfall KA, Wolfe P, Ordin DL, Krumholz HM. Spectrum of heart failure in older patients: Results from the national heart failure project. American Heart Journal 2002;143(3):412-7.

[25] Senni M, Tribouilloy CM, Rodeheffer RJ, et al. Congestive heart failure in the community: A study of all incident cases in Olmsted county, Minnesota, indkjdot. Circulation 1998;98(21):2282-9.

[26] Chen J, Radford MJ, Wang Y, Marciniak TA, Krumholz HM. Effectiveness of beta-blocker therapy after acute myocardial infarction in elderly patients with chronic obstructive pulmonary disease or asthma. J Am Coll Cardiol 2001;37(7):1950-6.

[27] Poole-Wilson PA, Swedberg K, Cleland JG, et al. Comparison of carvedilol and metoprolol on clinical outcomes in patients with chronic heart failure in the Carvedilol Or Metoprolol European Trial (COMET): randomised controlled trial. The Lancet 2003;362(9377):7-13.

[28] Callaerts-Vegh Z, Evans KL, Dudekula N, et al. Effects of acute and chronic administration of beta-adrenoceptor ligands on airway function in a murine model of asthma. Proc Natl Acad Sci USA 2004;101(14):4948-53.

[29] Abbott A. Beta-blocker goes on trial as asthma therapy. Nature 2004;432(7013):7.

[30] Bascelli LM, Oswald MA, Nashelsky J. Do beta-blockers worsen respiratory status for patients with COPD? J Fam Pract 2005;54(5):472-3.

[31] Salpeter S, Ormiston T, Salpeter E. Cardioselective betablocker use in patients with reversible airway disease. Cochrane Database Syst Rev 2001;(2): CD002992. 
[32] Salpeter S, Ormiston T, Salpeter E. Cardioselective betablockers for reversible airway disease. Cochrane Database Syst Rev 2002;(1): CD002992.

[33] Salpeter SR, Ormiston TM, Salpeter EE. Cardioselective beta-blockers in patients with reactive airway disease: a meta-analysis. Ann Intern Med 2002;137(9):715-25.

[34] Salpeter SR, Ormiston TM, Salpeter EE, Poole PJ, Cates CJ. Cardioselective beta-blockers for chronic obstructive pulmonary disease: a meta-analysis. Respir Med 2003;97(10):1094-101.

[35] Au DH, Bryson CL, Fan VS, et al. Beta-blockers as singleagent therapy for hypertension and the risk of mortality among patients with chronic obstructive pulmonary disease. Am J Med 2004;117(12):925-31.
[36] Sirak TE, Jelic S, Le Jemtel TH. Therapeutic update: non-selective beta- and alpha-adrenergic blockade in patients with coexistent chronic obstructive pulmonary disease and chronic heart failure. J Am Coll Cardiol 2004;44(3):497-502.

[37] Epstein PE, Fresh Air beta-blockade. Ann Intern Med 2002;137(9):766-7.

[38] British guideline on the management of asthma. Thorax 2003;58(Suppl. 1): i1-94.

[39] National Institutes of Health. Global initiative for asthma. Natl Heart Lung Blood Inst Publ No. 953659. Bethesda, MD: NHLBI 1995; 6.

Available online at www.sciencedirect.com

science@direct.

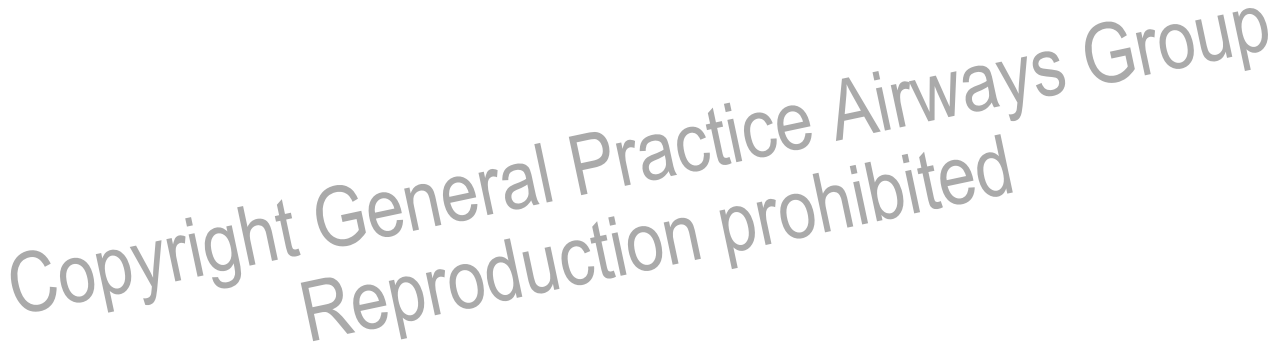

